International Journal of Technology 11(4) 774-783 (2020)

Received September 2019 / Revised March 2020 / Accepted June 2020

\title{
Characterization of Nitrogen Release in Modified Controlled-Release- Fertilizer using Rice Husk Biochar
}

\author{
Himawan Tri Bayu Murti Petrus ${ }^{1 *}$, Andreas Diga Pratama Putera ${ }^{1}$, Inasanti Pandan Wangi ${ }^{1}$, \\ Muhammad Aulia Ramadhian ${ }^{1}$, Hendrik Setiawan ${ }^{1}$, Agus Prasetya ${ }^{1^{* *}}$ \\ ${ }^{1}$ Sustainable Mineral Processing Research Group, Department of Chemical Engineering, Faculty of \\ Engineering, Universitas Gadjah Mada, Jl. Grafika 2, Yogyakarta 55281, Indonesia
}

\begin{abstract}
Rice husk biochar was added to modify ureic fertilizer in order to control nitrogen release in two methods: (1) mixed-granule and (2) as a coating. The mixed-granule fertilizer was made of varied compositions of rice husk biochar, ureic fertilizer, and clay as a binder, whereas the coating model was formulated from ureic fertilizer, biogas sludge, and clay as a core and coated with various compositions of biochar and clay. All of the samples were leached by $100 \mathrm{~mL}$ of water once every three days, and the leachate was analyzed for its nitrogen content. Of all samples, coated fertilizer with a composition of $20 \%$ biochar and $80 \%$ clay showed the slowest nutrient diffusion with an effective diffusivity (De) number of $2.85 \times 10^{-8} \mathrm{~cm} / \mathrm{s}^{2}$. The results show that both models increase fertilizer's ability to hold nitrogen longer than pure fertilizer. Both methods, mixed-granule and coated, showed slow release rate patterns, particularly at the beginning of the leaching process, and held the nitrogen content longer. Both models' release rates enable the modification of nitrogen release to meet the need for nitrogen in certain plantations.
\end{abstract}

Keywords: Coated fertilizer; Granule fertilizer; Nitrogen release; Rice husk biochar

\section{Introduction}

As an agrarian country with rice as its main staple, Indonesia is one of the main rice producers. Rice production has been increasing each year. This paddy grain is constituted by $20-30 \%$ husk, with rice husk waste amounting to the range of $11,000,000-14,000,000$ tons every year (Pode, 2016). However, rice husk can also be a valuable material if it is well processed. One example is to convert rice husks into biomass charcoal in the form of a briquette used for solid fuel combustion and gasified to produce syn-gas (Dafiqurrohman et al., 2016). The other example is for soil remediation, usually applied for clay or limestone (Shen et al., 2014) and the extraction of amorphous silica (Dhaneswara et al., 2020). In this work, we study the use of biochar from rice husk as a slow-release fertilizer agent.

One of the most popular methods to produce biomass is the slow pyrolisis method that turns biomass into charcoal. Charcoal's characteristically porous body provides an ideal habitat for soil microbes, but it is not consumed like other organic compounds. It can also hold the water and nutrients needed for crops (Shen et al., 2014). Biochar as a soil enhancer provides better humidity and fertility to the soil. This application also supports the carbon-

${ }^{*}$ Corresponding author's email: bayupetrus@ugm.ac.id, Tel.: 0274-555320, Fax.: 0274-555320

${ }^{* *}$ Corresponding author's email: aguspras@ugm.ac.id

doi: 10.14716/ijtech.v11i4.3520 
negative concept that minimizes the amount of carbon accumulation in the open air by adding it into the soil. Biochar also acts as a repair agent in the soil that changes its physical, chemical, and biological characteristics (Manyà et al., 2018; Zhu et al., 2019).

The usage of agricultural fertilizer in Indonesia is currently dominated by urea. Due to its ease of use, a high level of crop production and government subsidies further increase farmers' consumption of this nitrogen-based fertilizer (Winanto, 2018). Although currently, the government has started to promote the use of organic fertilizer due to its production limitation and higher price, urea remains the most-used fertilizer, providing about $60 \%$ of the total fertilizer needs in Indonesia each year.

Urea is specially created to supply nitrogen to crops, but unfortunately, there is a lack of efficiency in nitrogen supplying crops. From the amount of fertilizer shown, about $20-$ $65 \%$ of the urea is wasted. The nitrogen loss in the fertilizer used occurs because of evaporation as $\mathrm{NH}_{3}$, immobilization in soil pores or being carried away along with water. These inefficiencies cause adverse effects to the environment as excess nitrogen changes soil $\mathrm{pH}$, which kills microbes in the soil, and leached fertilizer can poison water that may be consumed by human and animals. To fulfil the nitrogen supply to crops and increase harvests, many farmers have increased their use of urea, which results in worse pollution and excessive use of fertilizer (Bari et al., 2007; Nardi et al., 2018).

To decrease the adverse effect of urea and reduce the consumption of urea, there is a need to increase usage efficiency. Several experiments have shown that one of the most efficient methods is controlling the release of various fertilizer constituents, like nitrogen, into the soil. An experiment by Zhang et al. (2018) revealed that, using controlled-release urea, the urea needed was decreased by $50 \%$, but the crop yield increased by $20-28 \%$. Another experiment examining the effect of controlled-release urea by Nardi et al. (2018) showed that the use of slow-release urea promoted higher microbial activity and lower-pH soil, which reduces the harmful effect of urea on the soil. The method of producing slowrelease fertilizer has itself been researched extensively, with Lateef et al. (2016) using nano-zeolite to encapsulate fertilizer, resulting in soil's increased water retention and promoting fertilizers' absorption efficiency into the soil. An experiment by Zhang et al. (2014) used graphene oxide (GO) as the coating for a potassium-based fertilizer. The release of potassium ions took place after seven to eight hours, with about $93.8 \%$ of potassium ions released from the fertilizer. An experiment using GO was also conducted by Andelkovic et al. (2018) for P-based fertilizer, which resulted in fertilizer absorption into the soil increasing to $99 \%$. Moreover, GO can be produced from graphite waste, providing a circular economy and increasing the feasibility of using GO a slow-release fertilizer or in any other utilization (Kusrini et al., 2019; Kusrini et al., 2020). Muharam et al. (2015) studied the release of potassium chloride from chitosan microspheres as a slow-release fertilizer.

In the current study, rice husk waste from agricultural production was made into biochar and utilized as an economically and environmentally friendly alternative coating agent for urea. The fertilizer in this experiment was modified with the addition of a mixture of rice husk biochar and clay. Biochar itself has been found to have a beneficial effect on soil and crop yields as its porous structure made up of carbon can, when added to the soil, increase the soil's ability to store nutrients and increase water retention, decreasing heavy metal content and regulating soil pH (Zornoza et al., 2016; Chen et al., 2018). Nitrogen release is also assessed using a mathematical model. The models are divided into two forms, granule mixture and coated fertilizer, as Figure 1 shows. 


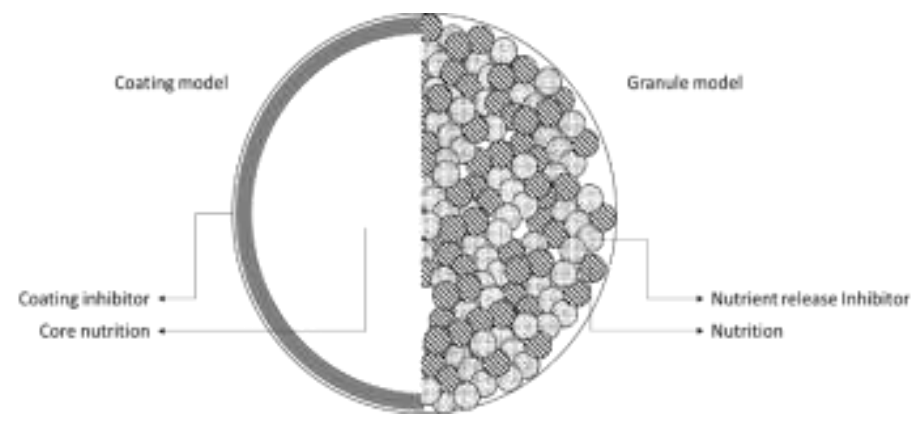

Figure 1 Difference between coated and granule-modified fertilizer

\section{Materials and Methods}

\subsection{Raw Materials}

The biochar used in this experiment was produced from biomass waste of rice husks. To obtain biochar, dried rice husk was processed using slow pyrolysis at a temperature of $300^{\circ} \mathrm{C}$ for 24 hours. The clay for this experiment was procured from Bayat Village, Central Java. The procured clay contained two important materials, $\mathrm{SiO}_{2}$ and $\mathrm{Al}_{2} \mathrm{O}_{3}$, stable at room temperature. Clay was used for its ability to bind materials and inertness. As the nitrogen source, commercial ureic fertilizers were used. This fertilizer contains $96 \%$ urea $\left(\mathrm{CH}_{4} \mathrm{~N}_{2} \mathrm{O}\right)$. Sludge from a biogas waste product was also used for its nitrogen content.

\subsection{Sample Preparation}

\subsubsection{Granule model}

Rice husk biochar and clay were milled using a mortar and sieved to a \#60 mesh size. All materials were then mixed using a granulator pan with a composition in accordance to Table 1.

Table 1 Granule fertilizer model composition (A; B; C) and coating formulation (D; E; F)

\begin{tabular}{cccc}
\hline Sample & Biochar (\%) & Urea (\%) & Clay (\%) \\
\hline A & 20 & 60 & 20 \\
B & 40 & 40 & 20 \\
C & 50 & 30 & 20 \\
\hline
\end{tabular}

\begin{tabular}{ccc}
\hline Sample & Biochar (\%) & Clay (\%) \\
\hline D & 20 & 80 \\
E & 50 & 50 \\
F & 60 & 40 \\
\hline
\end{tabular}

To obtain uniform samples, the granules obtained were sieved to obtain a \#14 mesh size.

\subsubsection{Coated model}

In the coated model, there were two steps to produce the fertilizer. The first step was to make the core, and the second step was the core coating. For all fertilizers, the core composition was fixed. However, the coating composition was varied to modify the nitrogen release.

a) Core production

Ureic fertilizer, sludge, and clay were mixed with 70\%: 20\%: 10\% w/w. Water was then added to the mixture to facilitate the binding process, and then the mixture was formed into a ball, each ball weighing $1 \mathrm{~g}$.

b) Coat production

For coating, there were three mixture composition variables to determine the nitrogen release for each composition, as Table 1 shows. For every $1.5 \mathrm{~g}$ of sample, biochar and clay were mixed, and water was then added to facilitate the binding process. The mixture was 
then used to coat the surface of the fertilizer core. In a comparison, some fertilizer cores were not coated in order to determine the nitrogen release phenomena without a coating.

\subsection{Leaching Experiments}

\subsubsection{Blank soil}

To ensure that the soil contained nitrogen in an uneventful amount, blank soil was leached using $100 \mathrm{~mL}$ of water once every three days for nine days, and the leachate was analyzed for its nitrogen content.

\subsubsection{Granule model}

Fertilizer was added at about $15 \mathrm{~g}$ for each pot. For Pot 1, pure ureic fertilizer was added, as much as $15 \mathrm{~g}$. For pots 2-3, Granule A was added, as much as 15 g. For pots 5-6, Granule B was added, as much as $15 \mathrm{~g}$. For pots 6-7, Granule C was added, as much as $15 \mathrm{~g}$. Every three days for nine days, the soils were leached with $100 \mathrm{~mL}$ of water. The leachate was then collected and analyzed for its nitrogen content.

\subsubsection{Coated model}

The coated fertilizer was added to the soil inside the leaching pot, as much as $5 \mathrm{~g}$ for each pot. For pot 1, the coatless fertilizer was added. For pots 2-3, Coated Fertilizer D was added. For pots 4-5 Coated Fertilizer E was added. And for pots 6-7, Coated Fertilizer F was added. The pots, then, were leached with $100 \mathrm{~mL}$ of water every three days for nine days. The leachate was then collected and analyzed for its nitrogen content.

\subsection{Nitrogen Analysis}

The leachate was analyzed for its nitrogen content in Laboratorium Analisis Tanah at UPN (Universitas Pembangunan Nasional) in Veteran, Yogyakarta. The resulting analysis will obtain the available nitrogen content in the leachate. The available nitrogen is the nitrogen that is readily taken up by the plant.

\subsection{Model of Coated Fertilizer}

The mathematical model can be used to predict the rate of nitrogen release both from the core and the coating. It becomes possible to obtain the diffusivity of nitrogen releasing through the medium (core and coating). From the diffusivity coefficient found in the model, the releasing characteristic can also be predicted if the composition and coating thickness vary. The mathematical model calculations are shown in Equations 1-19.

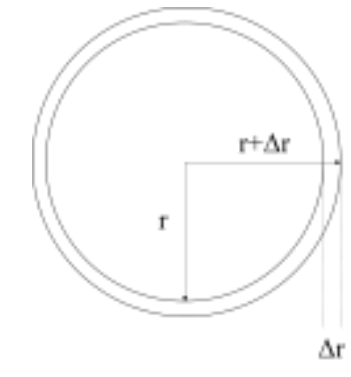

Figure 2 A two-dimensional diagram for a spherical volume element

Nitrogen mass balance in volume element $\left(4 . \pi \cdot \bar{r}^{2} . \Delta r\right)$

Rate of mass input - Rate of mass output $=$ Rate of mass accumulation

$$
\left.\left(4 . \pi \cdot r^{2} \cdot N_{A}\right)\right|_{r}-\left.\left(4 \cdot \pi \cdot r^{2} \cdot N_{A}\right)\right|_{r+\Delta r}=4 \cdot \pi \cdot \bar{r}^{2} \cdot \Delta r \cdot \frac{d C_{A}}{d t}
$$

while $N_{A}$, according Fick's laws:

$$
N_{A}=\left(N_{A}+N_{B}\right) x_{A}-D_{A B} \frac{d C_{A}}{d r}
$$

Assume $\left(N_{A}=N_{B} \approx 0\right)$ because the mass transfer is only the diffusion, thus 
From Equations 2 and 3, we have

$$
N_{A}=-D_{A B} \frac{d C_{A}}{d r}
$$

$$
\frac{\partial^{2} C_{A}}{\partial r^{2}}+\frac{2}{r} \frac{\partial C_{A}}{\partial r}=\frac{1}{D_{e}} \frac{\partial C_{A}}{\partial t}
$$

Equation 4 is a second-order partial ordinary differential equation. To find De, the finite difference approximation (FDA) method is used.

$$
\begin{gathered}
\frac{\partial^{2} C_{A}}{\partial r^{2}}=\frac{C_{A_{i+1}^{j+1}}^{j+2} C_{A_{i}^{j+1}}^{j+1}+C_{A_{i-1}^{j+1}}^{j+1}}{(\Delta r)^{2}} \\
\frac{\partial C_{A}}{\partial r}=\frac{C_{A_{i+1}^{j+1}}^{j+C_{A_{i-1}}^{j+1}}}{2 \cdot \Delta r} \\
\frac{\partial C_{A}}{\partial t}=\frac{C_{A_{i}^{j+1}}^{j+1}-C_{A_{i}}^{j}}{\Delta t}
\end{gathered}
$$

Effective diffusivity $\left(D_{e}\right)$ is the nitrogen diffusivity in the fertilizer. $D_{e}$ is obtained after the remaining mass in the fertilizer is calculated with the FDA method approach to the mass value of the experimental data. The output of Equation 4 is concentration distribution for each time and position variable, $C_{A}(r, t)$, in the fertilizer. The remaining nitrogen mass is obtained by Equation 8:

$$
M_{A}(t)=\sum_{i=1}^{N}\left(C_{A_{i}}^{j} \times 4 \pi r_{i}^{2} \Delta r\right)
$$

After the remaining mass is calculated, data fitting is done by Equation 9:

$$
S S E=\sum_{j=1}^{N t}\left(M_{A}^{j}-M_{D}^{j}\right)^{2}
$$

In the coated model, there are two values of $\mathrm{De}$, which are core diffusivity $\left(D_{e, 1}\right)$ and coating diffusivity $\left(D_{e, 2}\right)$, both diffused by nitrogen. The value of $D_{e, 1}$ can be obtained directly from solving Equations 1-9, with the following boundary condition:

The initial concentration of the fertilizer is Co, thus

$$
C_{A_{r}=r}^{t=0}=C_{0}
$$

Because the soil is leached, let nitrogen concentration outside the fertilizer be assumed as zero,

$$
C_{A_{r=R}}^{t=t}=0
$$

Nitrogen concentration inside the fertilizer is always at the maximum value,

$$
\frac{d C_{A}}{d r}\left|\begin{array}{l}
t=t \\
r=0
\end{array}\right|=0
$$

However, $D_{e, 2}$ cannot be obtained directly. $D_{e, 1}$ must be obtained prior to calculating $D_{e, 2}$. Therefore, the equation is split into two groups:

a. Core section,

$$
\frac{\partial^{2} C_{A, 1}}{\partial r^{2}}+\frac{2}{r} \frac{\partial C_{A, 1}}{\partial r}=\frac{1}{D_{e, 1}} \frac{\partial C_{A, 1}}{\partial t}
$$

b. Coating section,

$$
\frac{\partial^{2} C_{A, 2}}{\partial r^{2}}+\frac{2}{r} \frac{\partial C_{A, 2}}{\partial r}=\frac{1}{D_{e, 2}} \frac{\partial C_{A, 2}}{\partial t}
$$

With the following boundary conditions:

For the initial condition, the concentration of nitrogen in every position of the fertilizer is

$$
C_{A_{r=0 \sim r_{1}}^{t=0}}^{t=C_{0}}
$$

The initial concentration of nitrogen in the coating is zero, thus

$$
C_{A_{r}=r_{1} \sim r_{2}}^{t=0}=0
$$

The nitrogen concentration in the coating outside the surface is always zero, thus

$$
C_{A_{r=r_{2}}^{t}}^{t=t}=0
$$

In the interface of layers between the core surface and the coating inside the surface, the mass transport is the same, for $\mathrm{i}=\mathrm{n}$ : 


$$
\begin{gathered}
\left.\left(A \cdot N_{A, 1}\right)\right|_{i=n}=\left.\left(A \cdot N_{A, 2}\right)\right|_{i=n} \\
\left.\left(4 \pi r_{i}{ }^{2} \cdot k_{c, 1} \cdot\left(C_{A_{i}}^{j+1}-C_{A_{i-1}}^{j+1}\right)\right)\right|_{i=n}=\left.\left(4 \pi r_{i}{ }^{2} \cdot k_{c, 2} \cdot\left(C_{A_{i+1}}^{j+1}-C_{A_{i}}^{j+1}\right)\right)\right|_{i=n} \\
k_{c, 1} \cdot\left(C_{A_{n}}^{j+1}-C_{A_{n-1}}^{j+1}\right)=k_{c, 2} \cdot\left(C_{A_{n+1}}^{j+1}-C_{A_{n}}^{j+1}\right) \\
\frac{k_{c, 1}}{k_{c, 2}} \cdot C_{A}{ }_{n-1}^{j+1}+\left(-1-\frac{k_{c, 1}}{k_{c, 2}}\right) \cdot C_{A_{n}}^{j+1}+C_{A n+1}^{j+1}=0
\end{gathered}
$$

where, $\frac{k_{c, 1}}{k_{c, 2}}$ and $D_{e, 2}$ can be obtained by trial and error, using the Scilab program.

The model predicted the available nitrogen mass at various positions of the radius in the fertilizer for each time. These differential concentrations were integrated into total deposit nitrogen, and the value was compared to the experimental data from the analysis of leachate. The diffusivity for every variation is the value that gave the smallest sum of square of error (SSE) for the remaining total nitrogen content in the coated fertilizer obtained in the experiment. The method can be seen in Figure 3.

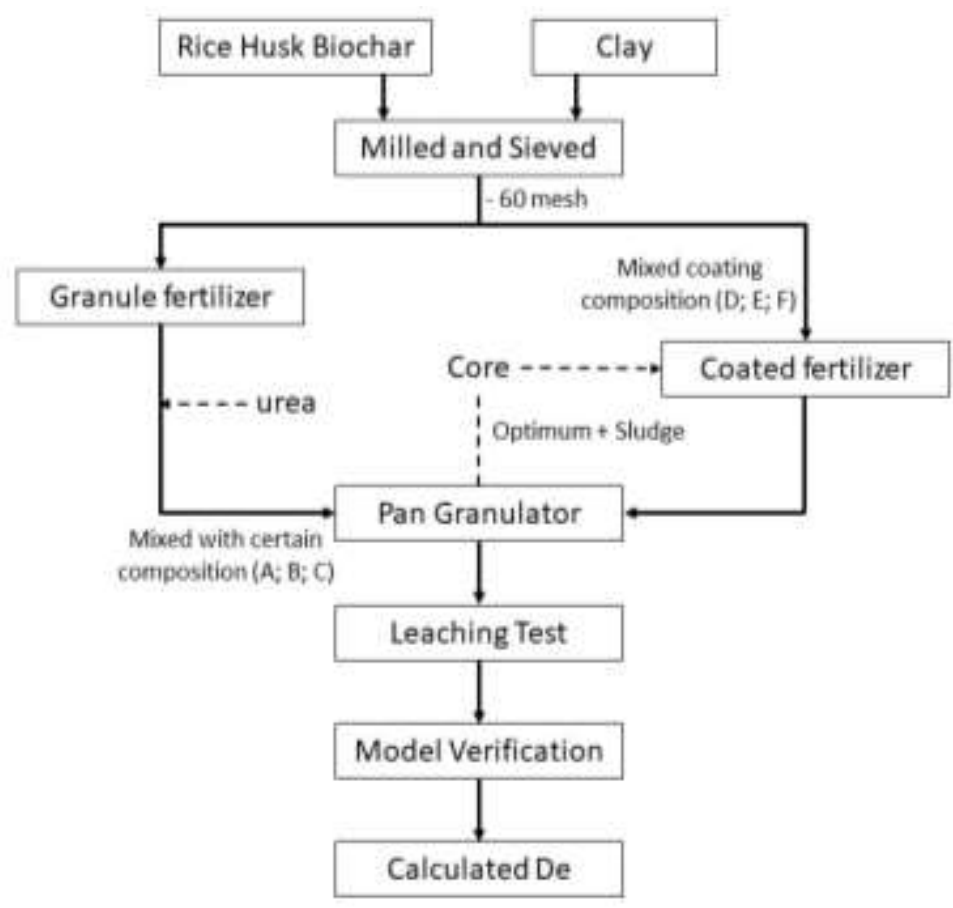

Figure 3 Method of this study on granule and coated modified fertilizer

\section{Results and Discussion}

\subsection{Granule Fertilizer}

\subsubsection{Raw material characterization}

Biochar's ability to retain nutrition was the effect of its porous carbon structure. Thus, further characterization was needed to determine the composition and surface characteristics of biochar that will affect its nutrition (fertilizer and water) retaining ability. This characterization was obtained using SEM-EDX (scanning electron microscopy-energy dispersive X-ray). The results are shown in Figure 4.

Figure $4 \mathrm{~b}$ shows that biochar has high carbon content on its surface that acts as a slowrelease agent for the fertilizer, and its porous carbon structure can increase the soil's nutrient retention ability. The presence of silica shows the binding potential of biochar to be easily granulated in the granulation process using water. The presence of oxygen further increases the binding ability of the biochar (Suliman et al., 2017). 


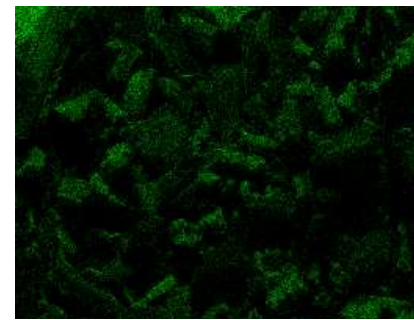

(a)

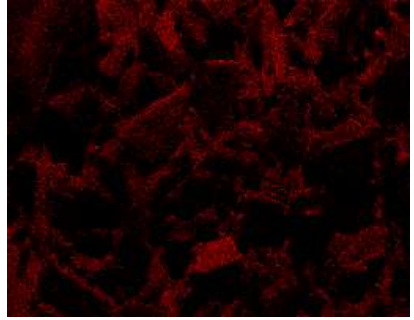

(b)

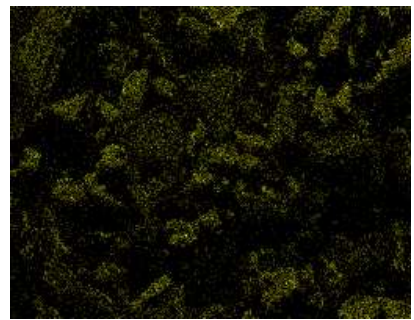

(c)

Figure 4 SEM-EDX results of raw material: (a) oxygen; (b) carbon; and (c) silica

Combined, these characteristics define and ascertain biochar's ability as an excellent coating material for controlled-release fertilizer. The granules that were made were mixed with soil in a pot and leached using water periodically. Also, to obtain the data on the total mass of the available nitrogen released, each sample was compared with standard samples (pure urea for the granule method and uncoated urea for the coating method). The blank soil had been leached and analyzed before the experiment; the analysis results found that the available nitrogen content in the soil was negligible. So, it can be concluded that the nitrogen content in the obtained samples came only from the fertilizer.

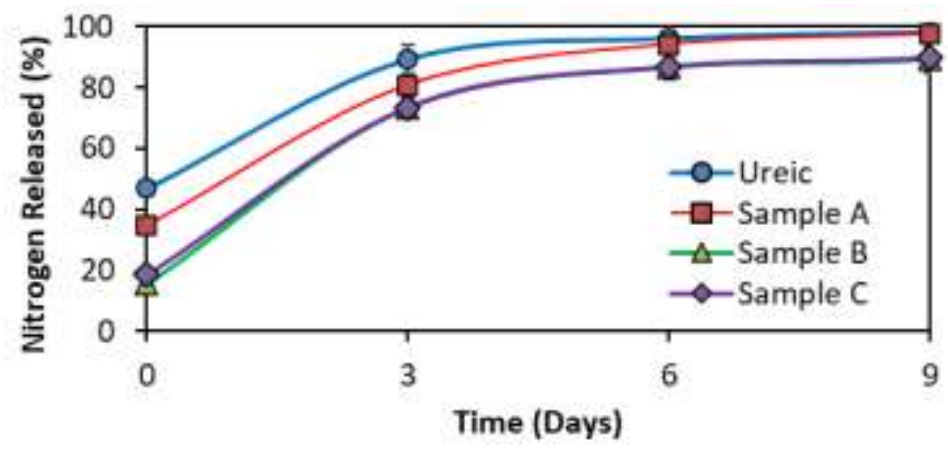

Figure 5 Cumulative percentage release of nitrogen for granule of uncoated fertilizers

Figure 5 shows that the addition of biochar into the fertilizer slowed the release of nitrogen into the soil. Compared to the other samples, Sample A-which only contained $20 \%$ of biochar - showed the highest rate of release. Sample B and Sample C contained $40 \%$ and $50 \%$ biochar, respectively. The initial release of nitrogen from Sample B was lower, at $9.35 \%$, while Sample C's initial release of nitrogen was at $18.70 \%$. But, over time, both samples' rates became close to one another. It can be concluded, however, that the best composition to control the release of nitrogen is Sample B, with $40 \%$ biochar, $40 \%$ urea, and $20 \%$ clay. For Sample A, which had the highest rate of release, the biochar at $20 \%$ composition proved not to be enough to slow the release significantly. Sample C, which had a higher initial release than Sample B, because of the high content of biochar-which is proven to be hydrophobic (Kinney et al., 2012) -involves a possibility of cracking that occurred at the start of the experiment, increasing the surface area for the nitrogen release. However, over time, the release rate of Sample B-with lower biochar content-started to resemble with Sample C.

\subsection{Coated Fertilizer}

Figure 6 shows that the effect of the coating slowed the release of nitrogen into the soil. The phenomenon observed in the experiment with the granule method showed that the more biochar was used in the composition, the more fragile the bond was due to its hydrophobic characteristic. This finding explains the phenomenon in which Sample D 
released the least available nitrogen, using $80 \%$ clay and $20 \%$ biochar as its coating. This result was because Sample D contained the most clay compared to the other samples, which resulted in its ability to maintain its shape.

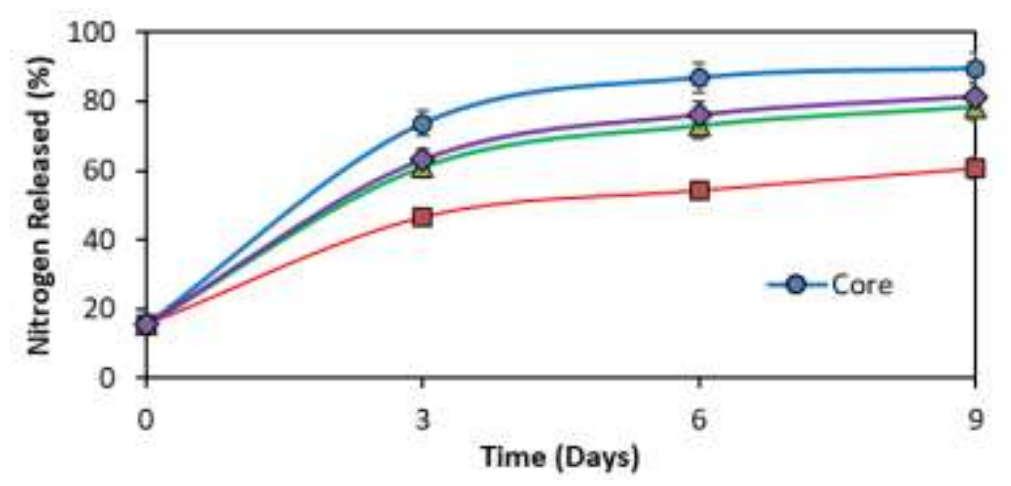

Figure 6 Cumulative percentage release of nitrogen for coated fertilizer

Samples E and F-which used 50\% and 60\% biochar for their coating material, respectively - could not maintain their shape because there was too little clay in their coats, which became brittle, and the nitrogen was easily leached by the water. In doing the calculation, some variables needed for Equation 19 were defined. These variables came from the parameters used in the experiment for the coated model fertilizer. The defective diffusivity coefficient (De) value could then be obtained using Equation 19, which was solved by Scilab. The values are shown in Table 2.

Table 2 Effective diffusivity coefficient for all coated modified fertilizer

\begin{tabular}{cc}
\hline Sample & De $\left(\mathrm{cm}^{2} / \mathrm{s}\right)$ \\
\hline Core & $7.360938 \mathrm{E}-07$ \\
Coating D & $2.850000 \mathrm{E}-08$ \\
Coating E & $7.700000 \mathrm{E}-08$ \\
Coating F & $7.600000 \mathrm{E}-08$ \\
\hline
\end{tabular}

Table 2 shows that the slowest release rate of nitrogen occurred in Sample D. A lower De number means a slower release of nitrogen (Irfan et al., 2018). The available nitrogen left in the fertilizer could then be calculated from the De value for the scale-up process. The result of the calculation, compared to the experimental data, is shown in Figure 7.

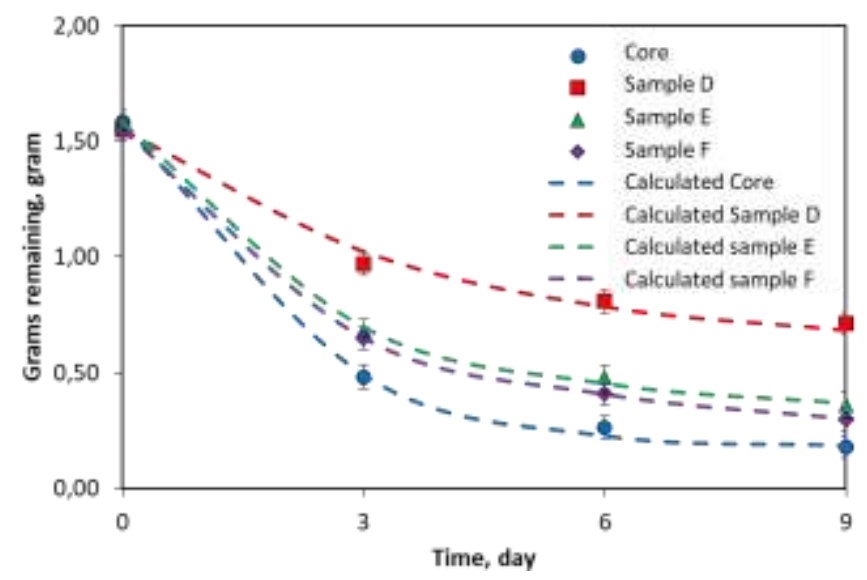

Figure 7 Data fitting of the available nitrogen remaining in the coated fertilizer 


\section{Conclusions}

The experiment with granule fertilizer showed that the addition of rice husk biochar can slow the release of nitrogen from the fertilizer. The results showed that the addition of more biochar into the granule slowed the release of nitrogen. The optimum amount, however, is $40 \%$ biochar, $40 \%$ urea, and 20\% clay, as shown. The addition of more biochar did not affect the release rate, other than the initial release. The experiment with coated fertilizer showed that decreasing biochar content in the coating slowed the nitrogen release. The slowest release of nitrogen was obtained with $80 \%$ clay and $20 \%$ biochar content. This phenomenon is due to biochar's hydrophobicity, which makes the coating more brittle at high biochar content, such that it will leak nitrogen. High clay content also acts as a binder to prevent the release of nitrogen into the soil. The De value obtained from the $80 \%$ clay and $20 \%$ biochar sample was $2.85 \times 10^{-8} \mathrm{~cm} / \mathrm{s}^{2}$. Because of the differences in nitrogen absorption for every type of plant, the coating method chosen can be suitable for the absorption system. This result shows that biochar is a prospective slow-release agent in minimizing the inefficiency of fertilizer usage. The use of biochar provides a circular economy for farmers dealing with rice husk waste from paddies' production.

\section{Acknowledgements}

We gratefully acknowledge the Department of Chemical Engineering, Energy Conservation and Environmental Protection Laboratory for the provided facilities to complete this study.

\section{References}

Andelkovic, I.B., Kabiri, S., Tavakkoli, E., Kirby, J.K., McLaughlin, M.J., Losic, D., 2018. Graphene Oxide-Fe(III) Composite Containing Phosphate - A Novel Slow Release Fertilizer for Improved Agriculture Management. Journal of Cleaner Production, Volume 185, pp. 97-104

Bari, N.M., Alam, M.Z., Sharmin, F.J., Rashid, M.H., 2007. Effect of Urea Fertilizer on Soil, Plant and Food Grain. In: International Conference on Biotechnology Engineering

Chen, Q., Qin, J., Sun, P., Cheng, Z., Shen, G., 2018. Cow Dung-derived Engineered Biochar for Reclaiming Phosphate from Aqueous Solution and Its Validation as Slow-release Fertilizer in Soil-Crop System. Journal of Cleaner Production, Volume 172, pp. 20092018

Dafiqurrohman, H., Surjosatyo, A., Gibran, F.R., 2016. Air Intake Modification for Pyrolysis Optimization on Rice Husk Fixed Bed Downdraft Gasifier for Maximum Capacity of 30 Kg/Hour. International Journal of Technology, Volume 7(8), pp. 1352-1361

Dhaneswara, D., Fatriansyah, J.F., Situmorang, F.W., Haqoh, A.N., 2020. Synthesis of Amorphous Silica from Rice Husk Ash: Comparing $\mathrm{HCl}$ and $\mathrm{CH}_{3} \mathrm{COOH}$ Acidification Methods and Various Alkaline Concentrations. International Journal of Technology, Volume 11(1), pp. 200-208

Irfan, S.A., Razali, R., KuShaari, K.Z., Mansor, N., Azeem, B., Versypt, A.N.F., 2018. A Review of Mathematical Modeling and Simulation of Controlled-Release Fertilizers. Journal of Controlled Release, Volume 271, pp. 45-54

Kinney, T.J., Masiello, C.A., Dugan, B., Hockaday, W.C., Dean, M.R., Zygourakis, K., Barnes, R.T., 2012. Hydrologic Properties of Biochars Produced at Different Temperatures. Biomass and Bioenergy, Volume 41 pp. 34-43

Kusrini, E., Oktavianto, F., Usman, A., Mawarni, D.P., Alhamidd, M.I., 2020. Synthesis, Characterization, and Performance of Graphene Oxide and Phosphorylated Graphene 
Oxide as Additive in Water-Based Drilling Fluids. Applied Surface Science, Volume 506, p. 145005

Kusrini, E., Suhrowati, A., Usman, A., Degirmenci, V., Khalil, M., 2019. Synthesis and Characterization of Graphite Oxide, Graphene Oxide and Reduced Graphene Oxide from Graphite Waste using Modified Hummers's Method and Zinc as Reducing Agent. International Journal of Technology, Volume 10(6), pp. 1093-1104

Lateef, A., Nazir, R., Jamil, N., Alam, S., Shah, R., Khan, M.N., Saleem, M., 2016. Synthesis and Characterization of Zeolite Based Nano-composite: An Environment Friendly Slow Release Fertilizer. Microporous and Mesoporous Materials, Volume 232, pp. 174-183

Manyà, J.J., Azuara, M., Manso, J.A., 2018. Biochar Production through Slow Pyrolysis of Different Biomass Materials: Seeking the Best Operating Conditions. Biomass and Bioenergy, Volume 117, pp. 115-123

Muharam, Y., Purwanto, W.W., Mulia, K., Wulan, P.P., Marzuki, I., Dewi, M.N., 2015. Mathematical Model Controlled Potassium Chloride Release Systems from Chitosan Microspheres. International Journal of Technology, Volume 6(7), pp. 1228-1237

Nardi, P., Neri, U., Matteo, G.D., Trinchera, A., Napoli, R., Farina, R., Subbarao, G.V., Benedetti, A., 2018. Nitrogen Release from Slow-Release Fertilizers in Soils with Different Microbial Activities. Pedosphere, Volume 28(2), pp. 332-340

Pode, R., 2016. Potential Applications of Rice Husk Ash Waste from Rice Husk Biomass Power Plant. Renewable and Sustainable Energy Reviews, Volume 53, pp. 1468-1485

Shen, Y., Zhao, P., Shao, Q., 2014. Porous Silica and Carbon Derived Materials from Rice Husk Pyrolysis Char. Microporous and Mesoporous Materials, Volume 188, pp. 46-76

Suliman, W., Harsh, J.B., Abu-Lail, N.I., Fortuna, A.M., Dallmeyer, I., Garcia-Pérez, M., 2017. The Role of Biochar Porosity and Surface Functionality in Augmenting Hydrologic Properties of a Sandy Soil. Science of the Total Environment, Volume 574, pp. 139-147

Winanto, A., 2018. Konsumsi Pupuk Urea 2017 Terbesar Dalam 10 Tahun Terakhir (2017 the Biggest Urea Fertilizer Consumption in the Last Decade). Available Online at https://ekonomi.bisnis.com/read/20180215/257/738966/konsumsi-pupuk-urea-

2017-terbesar-dalam-10-tahun-terakhir, Accessed on September 19, 2019

Zhang, M., Gao, B., Chen, J., Li, Y., Creamer, A.E., Chen, H., 2014. Slow-Release Fertilizer Encapsulated by Graphene Oxide Films. Chemical Engineering Journal, Volume 255, pp. 107-113

Zhang, S., Shen, T., Yang, Y., Li, Y.C., Wan, Y., Zhang, M., Tang, Y., Allen, S.C., 2018. ControlledRelease Urea Reduced Nitrogen Leaching and Improved Nitrogen Use Efficiency and Yield of Direct-Seeded Rice. Journal of Environmental Management, Volume 220, pp. 191-197

Zhu, Y., Tang, W., Jin, X., Shan, B., 2019. Using Biochar Capping to Reduce Nitrogen Release from Sediments in Eutrophic Lakes. Science of the Total Environment, Volume 646, pp. 93-104

Zornoza, R., Moreno-Barriga, F., Acosta, J.A., Muñoz, M.A., Faz, A., 2016. Stability, Nutrient Availability and Hydrophobicity of Biochars Derived from Manure, Crop Residues, and Municipal Solid Waste for Their Use as Soil Amendments. Chemosphere, Volume 144, pp. $122-130$ 